\title{
Alzheimer genetics, part I
}

\author{
Decoding Darkness: The Search for the Genetic Causes of \\ Alzheimer's Disease \\ by Rudolph E. Tanzi \& Ann B. Parson \\ Perseus Publishing, \$26.00, ISBN 0-7382-0195-2, 2000
}

\section{Reviewed by Joseph D. Buxbaum}

Department of Psychiatry, Mount Sinai School of Medicine, New York, New York, USA

Decoding Darkness, by Rudolph Tanzi and Ann Parson, is an enjoyable, well-written book that details the search and ultimate discovery of genes underlying Alzheimer disease. It is a good read and can be enjoyed by the lay public, by scientists in other disciplines and even by Alzheimer researchers - who will at the very least be amused at how the authors have tip-toed through various political minefields.

The book is written almost entirely from the perspective of co-author Tanzi. This is a departure from the disinterested, dispassionate style that many scientists adopt, and makes for an effective and engaging narrative. Tanzi was deeply involved in Alzheimer research throughout the period covered by the narrative and was a key player in many of the advances mentioned. His perspective is thus first-hand and informed. The story is well-referenced, and many people in the field are given an opportunity to voice their opinions and even dispute certain events.

The story really picks up with the sequencing in the mid 1980s of the amyloid (A $\beta$ ) peptide, which accumulates in amyloid plaques in Alzheimer disease. The race to identify the protein from which $A \beta$ is derived culminated in the identification of the amyloid protein precursor (APP) by several groups, including one of which Tanzi was a member. Because the gene APP mapped to the critical Down syndrome region of chromosome 21 (and given that all people with
Down syndrome develop Alzheimer neuropathology), it was thought that mutations in APP might account for the rare, early onset forms of Alzheimer disease that are inherited in an autosomal-dominant fashion. It took several years and quite a bit of searching, but ultimately mutations in $A P P$ were identified in exceedingly rare cases of early onset Alzheimer disease. Genes with much greater epidemiological impact (that is, those encoding presenilin-1 (PSEN1) and apolipoprotein $\mathrm{E}(\mathrm{APOE})$ ) were identified by the classic methods of linkage analysis and positional cloning. Another gene, PSEN2, was identified by its homology to PSEN1.

The Alzheimer research community has been quarrelsome at times. The stakes are very high and the competition fierce, and passion about the science sometimes spills over into personal confrontation. I must admit that I was very curious (in a wicked sort of way) to see how some of the more contentious events would be dealt with. The conflicts are identified and scientists are given a voice to express their opinions and even to admit to regrets about some of their actions. Tanzi does not spare himself, and does not shy away from personal matters. His marriage and divorce are noted, and his passion for lucid dreaming, which must have raised a few eyebrows over the years, is presented without apology. In aggregate, the authors do a good job of describing the personal face of research and the resultant conflicts, without belaboring the latter.
Personally, and perhaps for the readers of Nature Genetics, one of the most interesting side stories touched on in Decoding Darkness is the birth of modern methods of linkage analysis and positional cloning. Tanzi began his career in the laboratory of Jim Gusella, where restriction fragment length polymorphisms and then microsatellites were first used to track down the gene mutated in people with Huntington disease. He was also involved in the mapping of chromosome 21 . What makes this story so fascinating is the realization that these methods, first introduced such a short time ago, have already led to the discovery of virtually all of the genes underlying common mendelian disorders. Moreover, there is the growing awareness that the useful life of these methods is coming to an end, as the search for genes mutated in common, complex diseases, caused by many interacting genes of weak effect, demands other methods or improbably large sample sizes. The discovery of Alzheimer genes has paralleled this path, with the causal, autosomal-dominant gene mutations (in APP and PSEN1) and the gene variants conferring greatest risk (APOE) identified by traditional methods of linkage analysis, whereas the genes of weaker effect (such as the $A 2 M$ polymorphism) required association studies.

For the lay reader, or scientist in a more distant discipline, the book provides a window into biomedical research, the motivations of the researchers, the stakes and the energy. In addition, the book captures the great optimism that pervades the Alzheimer research community. The general feeling is that the molecular basis of the disease has been extensively clarified and that novel drug targets are at hand, soon to be followed by effective therapies. For scientists in molecular research, particularly younger scientists, Decoding Darkness captures the excitement of the hunt that has played out in the past 15 years and recounts what is certainly one of the great success stories in biomedical research. Finally, for Alzheimer researchers, it is a good gift to give to friends and family - so that they can finally understand what it is that you do! 